\title{
Rancang Bangun Robot Bawah Air Menggunakan Sistem Ballast Berbasis Rov (Remotely Operated Vehicle) Dengan Frekuensi $433 \mathrm{Mhz}$
}

\author{
Edi Mulyana, Neni Utami Adiningsih, Cecep Ahmad Fauzi \\ Jurusan Teknik Elektro, Fakultas Sains dan Teknologi \\ Universitas Islam Negeri Sunan Gunung Djati Bandung \\ edim@uinsgd.ac.id, nua@bdg.centrin.net.id, cecepahmadfauzi93@gmail.com
}

\begin{abstract}
Abstrak - ROV (Remotely Operated Vehicle) adalah salah satu jenis robot bawah air yang dikendalikan menggunakan remote control. Komunikasi antara remote control dengan robot dapat melalui media kabel atau tanpa kabel (wireless). Dalam melakukan misi penyelaman sebuah robot bawah air harus dapat bergerak dengan bebas tanpa terbatasi oleh kabel sehingga pemilihan remote control tanpa kabel lebih efisien dari pada menggunakan kabel. Selain itu juga robot bawah air harus dapat mengapung, melayang dan tenggelam sehingga dibutuhkan sebuah sistem ballast pada robot ROV. Tujuan dari penelitian ini adalah merancang sebuah ROV tanpa kabel dengan frekuensi 433 Mhz yang dilengkapi sistem ballast. Penggunaan frekuensi $433 \mathrm{Mhz}$ diharapkan mampu membuat jangkauan robot lebih jauh saat bergerak dibandimgkan dengan frekuensi 2,4 Ghz. Sistem Ballast pada penelitian ini memanfaatkan prinsip kerja dari ompa air untuk mengisi dan membuang air dari dalam tangki. Volume tangki ballast sebesar 2340,96 $\mathrm{cm}^{3}$ dan volume ROV sebesar 3447,2 $\mathrm{cm}^{3}$. Waktu yang diperlukan untuk mengisi menngeluarkan air adalah 60 detik. Jarak jangkauan robot saat bergerak di permukaan yaitu 15 meter dan saat menyelam yaitu 30 $\mathrm{cm}$. Dengan rata - rata kecepatan robot ketika bergerak dipermukaan dan didalam air adalah 0,0299 $\mathrm{m} / \mathrm{s}$ dan $0,0293 \mathrm{~m} / \mathrm{s}$.
\end{abstract}

Kata kunci: ROV (Remotely Operated Vehicle), Sistem Ballast, Frekuensi 433 Mhz, Remote control, Wireless

\section{Pendahuluan}

Teknologi robot banyak diterapkan dalam berbagai bidang kehidupan. Ada yang digunakan di bidang industri, observasi, pendidikan dan lain - lain. Kemajuan teknologi robot tidak lepas dari banyaknya penggunaan chip Mikrokontroler sebagai otak dan pusat kendali dari sebuah robot.

Ada beberapa tipe robot yang secara umum dibagi menjadi dua kelompok yakni robot manipulator dan robot yang dapat bergerak (mobile robot). Robot manipulator dicirikan dengan memiliki lengan (arm robot) dan banyak digunakan untuk robot industri. Sedangkan mobile robot merupakan robot yang dapat bergerak berpindah tempat meskipun nantinya robot tersebut juga dipasang manipulator. Robot yang dapat bergerak (mobile robot) dapat dikelompokkan lagi menjadi tiga yaitu robot daratan (ground robot), robot air (underwater robot), dan robot terbang (aerial robot)[2]. ROV (Remotely Operated Vehicle) adalah salah satu jenis kapal selam dengan ukuran mini yang bertenaga listrik dan dikontrol dari pusat, dapat bermanuver sesuai perintah manusia dengan pendorong (thruster) hidrolik atau elektrik dan dioperasikan oleh seseorang di atas kapal [1].

Berdasarkan penelitian yang dilakukan oleh Made Santo Gitakarma, Ketut Udy Ariawan, Nyoman Arya Wigraha dengan judul "Alat Bantu Survey Bawah Air Menggunakan AMOBA, Robot Berbasis ROV" robot bawah air ini dikendalikan oleh sebuah remote PS2 yang dihubungkan dengan kabel sepanjang 15 meter ke mikrokontroler MCS-51 selaku pusat kendali

TELKA, Vol.2, No.2, November 2016, pp. 126 137

ISSN (e): 2540-9123

ISSN (p): 2502-1982 
robot. Delapan buah pompa air dipasang pada robot sebagai aktuator yang berfungsi untuk melakukan manuver di dalam air[2]. Penggunaan RC (Remote Control) dengan media kabel dianggap kurang efesien karena dapat menghambat gerakan robot. Sedangkan penggunaan RC (Remote Control) tanpa kabel (wireless) dianggap lebih efisian karena robot dapat bergerak tidak terbatas oleh kabel.

Pada penelitian lain yang dilakukan oleh Laode Ma'mun, Fakhrul Risal Djumingan, Faizal Arya Samman, dan Zulfajri Basri Hasa dengan judul "Kapal Selam Mini Tanpa Awak Untuk Eksplorasi Bawah Laut" robot bawah air yang dirancang berbasis ROV (Remotely Operated Vehicle). Pengendali robot menggunakan remote PS3 tanpa kabel (wireless) dengan frekuensi kerja 2,4 Ghz, mikrokontroler ATMega 2560 sebagai pusat kendali, 4 buah motor DC dipasang sebagai aktuator. Rangka robot dibuat dari pipa PVC. Pada penelitian ini masih ada beberapa permasalahan yang belum terpecahkan diantaranya pengontrolan yang jaraknya kurang jauh dan gaya tekan ke atas yang masih besar[1].

Untuk penelitian yang dilakukan oleh Yanuar Chandra dengan judul "Rancang Bangun Sistem Ballast pada ROV (Remotely Operated Vehicle)" dibuatlah sebuah sistem ballast pada robot bawah air yang dapat membuat robot mengapung, melayang dan tenggelam di dalam air. Sistem ballast yang dibuat menggunakan sistem pompa air. Sistem ballast ini akan mengurangi gaya tekan ke atas dari robot[3].

Pada penelitian ini akan dirancang dan diimplementasikan sebuah robot bawah air yang dikontrol dengan remote tanpa kabel yang mempunyai frekuensi kerja di bawah 2,4 Ghz yaitu frekuensi 433 Mhz. Robot ini juga menggunakan sistem ballast untuk mengatur gaya tekan ke atas dan ke bawah. Sebuah robot bawah air dalam melakukan misi penyelaman harus di dukung dengan manuver robot yang mobile (bebas) seperti maju, mundur, belok kanan, belok kiri, mengapung, melayang dan tenggelam. Didasari hal tersebut maka laporan tugas akhir ini berjudul "Rancang Bangun Robot Bawah Air menggunakan Sistem Ballast Berbasis ROV (Remotely Operated Vehicle) dengan Frekuensi 433Mhz".

\section{Landasan Teori}

\subsection{Robot Bawah Air (Underwater)}

Robot bawah air adalah salah satu tipe mobile robot yang aplikasinya ditujukan untuk melakukan kegiatan di bawah air. Secara umum robot bawah air dikelompokan atas dua jenis yaitu AUV (Autonomous Underwater Vehicle) dan ROV (Remotely Operated Vehicle). AUV adalah jenis robot bawah air yang bersifat autonomous (otonom), robot dapat bergerak dan melakukan kegiatan sendiri, berdasarkan program yang telah ditanamkan di dalam chip-nya. Hal ini ditunjang dengan dukungan dari sensor- sensor yang disertakan pada robot tersebut. Sedangkan ROV adalah robot bawah air yang dikendalikan oleh operator dalam pengoperasiannya, dan didukung oleh perangkat kendali (remote control) dalam pengoperasiannya. Robot penyelam termasuk dalam jenis robot atau kendaraan bawah air yang tergolong ROV. Robot penyelam adalah robot yang mampu bergerak di dalam air. Gerakan yang dapat dilakukan adalah naik dan turun/menyelam. Gerakan ke atas timbul akibat adanya gaya dorong dari putaran propeller, sedangkan untuk gerak menyelam disebabkan oleh berat beban dari robot (saat kondisi motor off)[2].

\subsection{Komunikasi Wireless (Nirkabel)}

Wireless yaitu koneksi antar suatu perangkat dengan perangkat lainnya tanpa menggunakan kabel atau metode untuk mengirimkan sinyal melalui suatu ruangan bukannya menggunakan kabel. Gelombang radio dan sinar infra merah biasa digunakan untuk komunikasi wireless. Dalam sistem komunikasi wireless terdapat perangkat atau bagian umum dari gelombang yang berperan dan menjadi bagian utuh dari sistem komunikasi ini, yaitu [5]:

1. Gelombang Elektromagnetik 
2. Gelombang Mikro

3. Gelombang Radio

4. Infra Merah

5. Satelit.

\subsection{Sistem Ballast}

Pada dasarnya, ada dua cara untuk menenggelamkan kapal selam yaitu dengan cara menyelam secara dinamis dan statis. Sistem dinamis adalah sistem dengan metode penyelaman menggunakan sirip atau biasa disebut dengan hidroplane. Dibantu dengan kecepatan dari kapal selam tersebut untuk membantu pergerakan kapal selam agar dapat menyelam dan mengapung di air. Sedangkan untuk kapal selam statis yaitu memiliki proses penyelaman dengan cara mengubah berat dari kapal selam misalnya dengan cara mengisi tangki ballast yang bertujuan untuk melakukan pergerakan penyelaman dan untuk melakukan pergerakan mengapung, dilakukan dengan memompa air dari tangki ballast keluar dari ROV. Berikut ini adalah contoh gambar proses penyelaman secara dinamik serta proses penyelaman secara static dengan menggunakan salah satu model sistem ballast yaitu dengan sistem pompa [3].

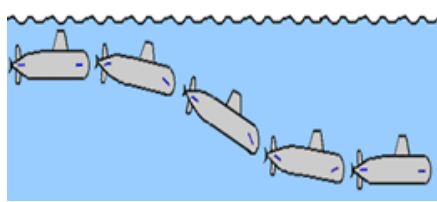

Gambar 1. Menyelam Secara Dinamik [3]

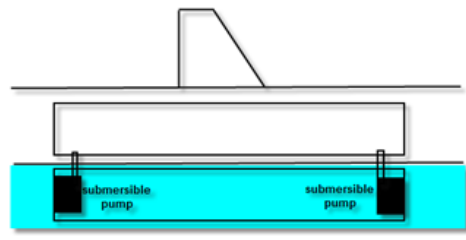

Gambar 2. Menyelam secara static dengan bantuan sistem ballast[3]

Bouyancy adalah suatu faktor yang sangat penting di dalam penyelaman. Selama melakukan pergerakan dalam air penyelam harus dapat mempertahankan posisi netral (Bouyancy Neutral). Keadaan mengapung "Bouyancy Positif" terjadi apabila berat kapal lebih kecil dari gaya apung sehingga dapat menyebabkan kapal selam naik ke permukaan. Keaadaan "Bouyancy Negatif" terjadi apabila berat kapal selam lebih besar dari gaya apung dan menyebabkan kapal selam tenggelam. "Buoyancy Neutral" mengacu pada kondisi di mana berat kapal selam sama dengan gaya apung, sehingga mengalami pergerakan melayang[3].

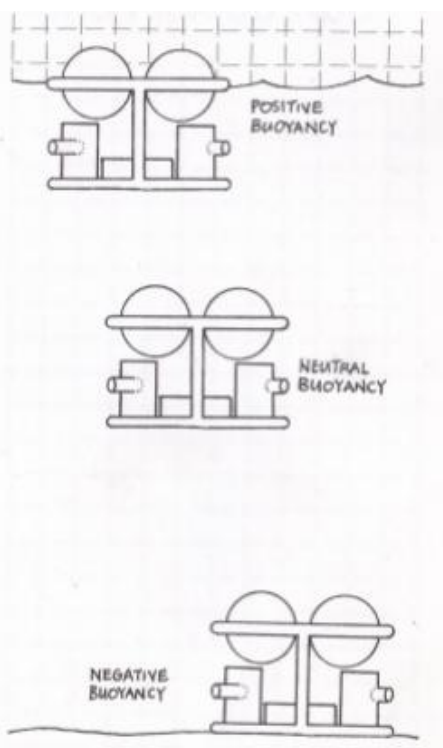

Gambar 3. Bouyancy Robot[4]

ISSN (e): 2540-9123 


\section{Metodologi Penelitian}

Metodologi penelitian yang digunakan dalam penyusunan tugas akhir ini meliputi berbagai tahapan. Berikut adalah diagram alir dari proses penelitian ini:

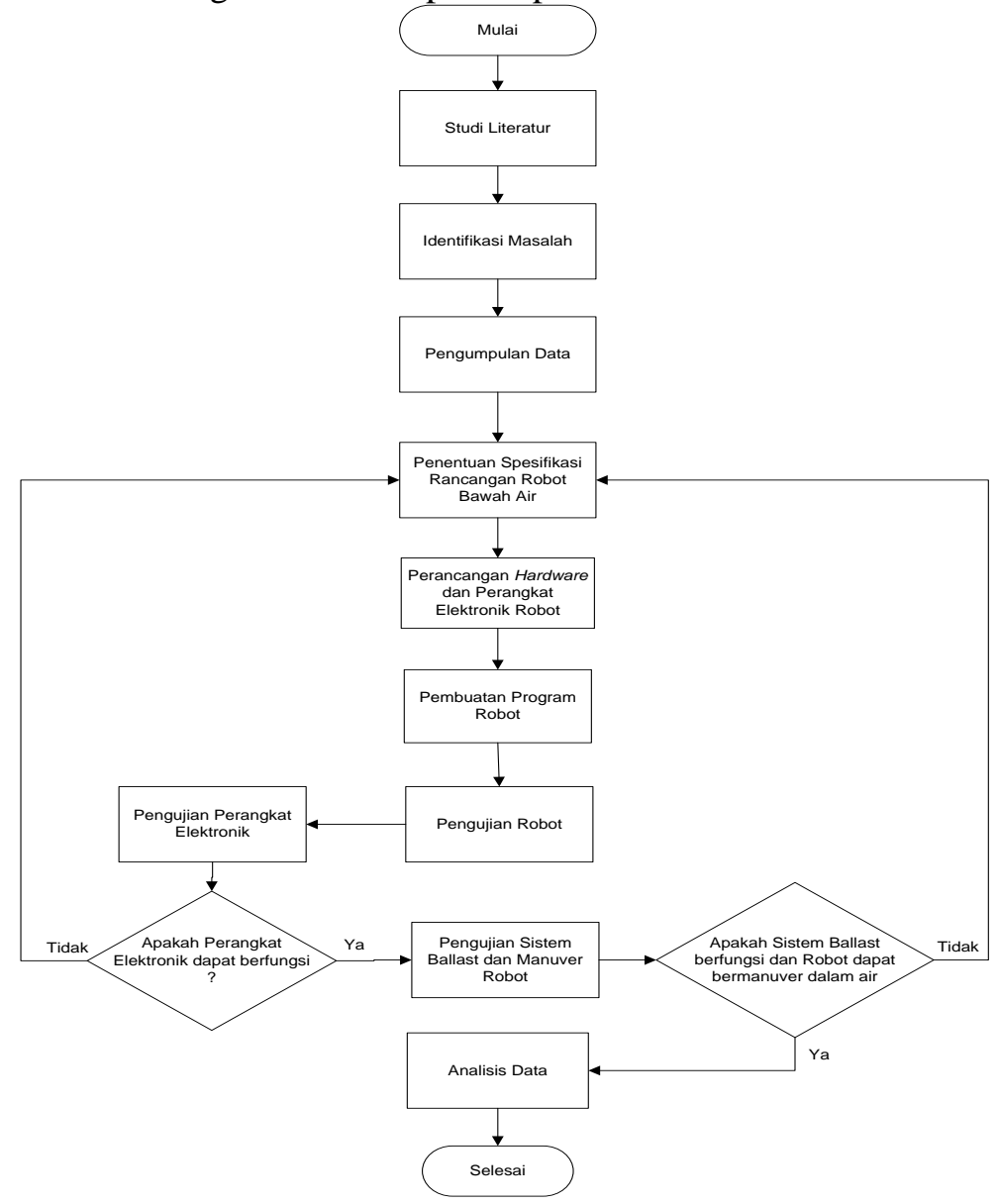

Gambar 4. Flowchart Metodologi Penelitian

\section{Perancangan dan Implementasi}

Pada bab ini berisikan tentang prosedur perancangan robot bawah air. Perancangan terdiri dari 2 bagian yaitu perancangan perangkat keras (hardware) dan perancangan perangkat lunak (software). Perancangan perangkat keras dibagi menjadi 2 tahapan yaitu merancang rangkaian elektronika dan merancang rangka (body) robot serta sistem ballast nya. Sedangkan untuk perancangan perangkat lunak hanya membuat program untuk menjalankan robot.

Perancangan perangkat elektronik untuk robot bawah air dalam penelitian ini terdiri dari 2 bagian yaitu bagian pengirim (transmitter) dan bagian penerima (receiver). Seperti diperlihatkan pada gambar 5 dan 6 berikut. Untuk bagan bagian pengirim dapat dilihat pada gambar 5 dibawah ini.

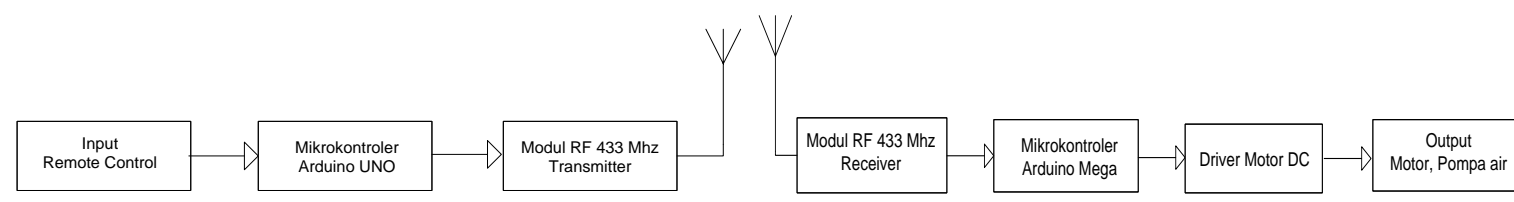

Gambar 5. Bagian Pengirim (Transmitter)

Gambar 6. Bagian Penerima (Receiver) 
Pada bagian pengirim terdapat remote control sebagai input, mikrokontroler arduino UNO, modul transmitter RF $433 \mathrm{Mhz}$ untuk komunikasi jarak jauh dan antena sebagai media pengirimnya. Sedangkan pada bagian penerima terdapat antena sebagai penangkap sinyal, modul receiver RF 433 Mhz sebagai media komunikasi jarak jauh tanpa kabel, Mikrokontroler Arduino Mega, output robot yang dikontrol yaitu motor DC dan pompa air pada sistem ballast.

Berdasarkan bagan bagian pengirim (transmitter) diatas maka dibuatlah rangkaian input berupa remote control. Langkah pertama yaitu mendesain rangkaian elektronik dalam sebuah software yang bernama Altium Designer.

Rangkaian remote control tersusun dari beberapa komponen yaitu push button switch, resistor dan header yang diintergrasikan menjadi satu kesatuan alat. Remote control ini akan memberikan masukan pada Arduino UNO untuk memerintah robots seperti diperlhatkan pada gambar 7 .

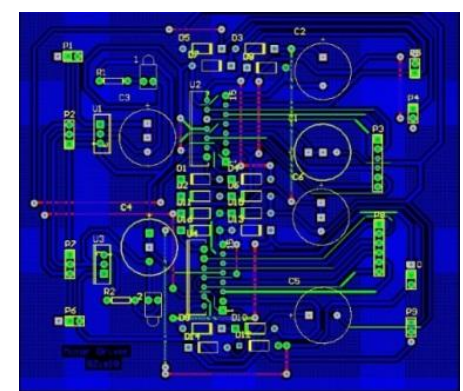

Gambar 7. Layout PCB Rangkaian Remote Control

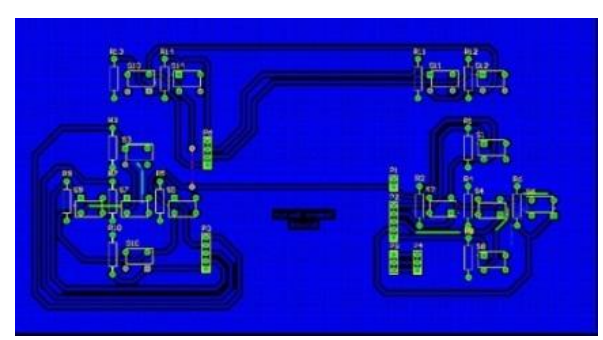

Gambar 8. Layout PCB Rangkaian Motor Driver

Pada bagan bagian penerima (receiver) terdapat rangkaian motor driver yang berfungsi sebagai penguat sinyal dari Arduino ke motor. Motor driver ini tersusun dari beberapa komponen yaitu IC L298N, dioda, header, LED, kapasitor $220 \mathrm{uF}$, IC regulator 7805 , dan resistor $1 \mathrm{~K}$ ohm. Langkahnya sama seperti pada rangkaian remote control pertama rangkaian didesain pada software Altium Designer.

Gambar 8. adalah tampilan layout PCB dari rangkaian motor driver secara keseluruhan. Dalam layout tersebut rangkaian motor driver dibuat ganda menggunakan 2 buah IC L298N sehingga outputnya dapat mengontrol lebih dari 2 motor.

Perancangan rangka robot dan tangki ballast dilakukan melalui beberapa tahapan yang pertama yaitu perhitungan rangka robot dan tangki ballast, yang kedua yaitu pembuatan desain pada software autocad 2004.

Adapun perhitungan dari seluruh bagian rangka robot dan tangki ballast yaitu :

1. Rangka Utama

Diameter pipa $(\mathrm{d})=1,27 \mathrm{~cm}$

$\mathrm{r}($ jari - jari $)=0,635 \mathrm{~cm}$

$\mathrm{h}$ (tinggi) $=38 \mathrm{~cm}$

$\mathrm{V}=\pi r^{2} h=3,14 \times 0,635 \times 0,635 \times 38=48,2 \mathrm{~cm}^{3} \times 4=192,8 \mathrm{~cm}^{3}$

$\mathrm{h}$ (tinggi) $=28 \mathrm{~cm}$

$\mathrm{V}=\pi r^{2} h=3,14 \times 0,635 \times 0,635 \times 28=35,5 \mathrm{~cm}^{3} \times 2=71 \mathrm{~cm}^{3}$

2. Kaki - kaki

$\mathrm{h}($ tinggi $)=12 \mathrm{~cm}$

$\mathrm{r}($ jari - jari $)=0,635 \mathrm{~cm}$

$\mathrm{V}=\pi r^{2} h=3,14 \times 0,635 \times 0,635 \times 12=15,2 \mathrm{~cm}^{3} \times 4=60,8 \mathrm{~cm}^{3}$

$\mathrm{h}($ tinggi $)=14 \mathrm{~cm}$ 
$\mathrm{V}=\pi r^{2} h=3,14 \times 0,635 \times 0,635 \times 14=17,8 \mathrm{~cm}^{3} \times 2=35,6 \mathrm{~cm}^{3}$

3. Volume kotak (tempat)

Panjang $=21 \mathrm{~cm}$

Lebar $=21 \mathrm{~cm}$

Tinggi $=7 \mathrm{~cm}$

$\mathrm{V}=\mathrm{p} \times 1 \times \mathrm{t}=21 \times 21 \times 7=3087 \mathrm{~cm}^{3}$

4. Tabung Ballast

Diameter pipa $(\mathrm{d})=10,16 \mathrm{~cm}$

$\mathrm{r}($ jari - jari $)=5,08 \mathrm{~cm}$

$\mathrm{h}($ tinggi $)=30 \mathrm{~cm}$

$\mathrm{V}=\pi r^{2} h=3,14 \times 5,08 \times 5,08 \times 30=2430,96 \mathrm{~cm}^{3} \times 2=4861,92$

Volume total $=($ rangka utama $)+($ kaki - kaki $)+($ kotak elektronik $)+($ tangki ballast $)=$ $192,8+71+60,8+35,6+3087+4861,92=8309,12 \mathrm{~cm}^{3}$

5. Volume Pemberat

Diameter pipa $(\mathrm{d})=10,16 \mathrm{~cm}$

$\mathrm{r}($ jari - jari $)=5,08 \mathrm{~cm}$

$\mathrm{h}$ (tinggi) $=14 \mathrm{~cm}$

$\mathrm{V}=\pi r^{2} h=3,14 \times 5,08 \times 5,08 \times 14=1134,45 \mathrm{~cm}^{3} \times 2=2268,9 \mathrm{~cm}^{3}$

Jadi Volume total + Volume pemberat $=8309,12+2268,9=10308,02 \mathrm{~cm}^{3}$

Setelah dilakukan perhitungan pada rangka robot dan tangki ballast maka diperoleh acuan untuk membuat rancangan dan bentuk dari keseluruhan rangka robot. Gambar atau desain dari rangka robot dibuat dengan software yang bernama autocad. Gambar 9 dibawah ini adalah gambar keseluruhan desain dari rangka dan tangki ballast robot.

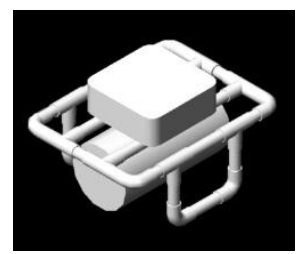

Gambar 9. Bentuk Keseluruhan Rangka dan Tangki Ballast dalam Bentuk 3D

Perancangan robot bawah air yang telah dilakukan baik itu perancangan perangkat elektronik maupun perancangan rangka robot akan diimplementasikan menjadi sebuah alat. Implementasi perangkat elektronik terdiri dari 2 bagian yaitu bagian pengirim (transmitter) dan bagian penerima (receiver).

Dibawah ini adalah Implementasi PCB remote control di bagian pengirim (transmitter).

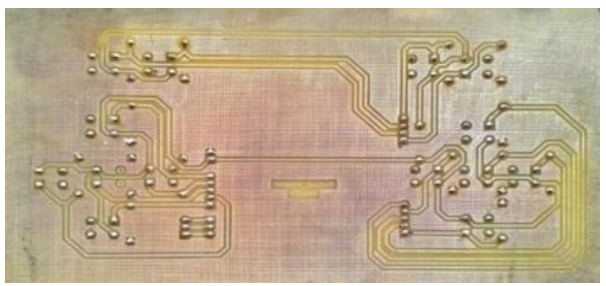

Gambar 10. Implementasi PCB Rangkaian Remote Control Tampak Bawah

Gambar 10 adalah tampak bawah dari implementasi rangkaian remote control yang telah di cetak pada sebuah papan PCB. Rangkaian remote control tidak dapat bekerja sendiri karena rangkaian ini hanya difungsikan sebagai pemberi masukan (input) ke mikrokontroler sehingga dirangkai dengan alat yang lain menjadi sebuah kesatuan alat yang utuh. 


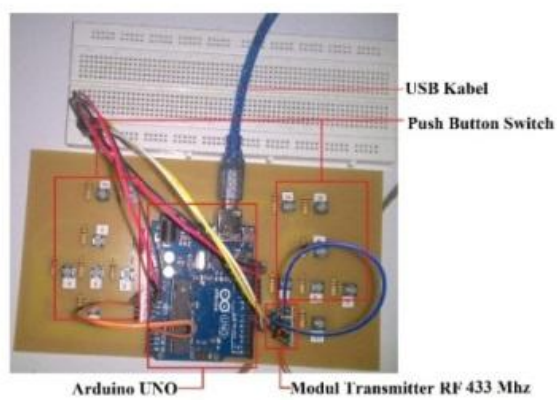

Gambar 11. Implementasi Bagian Pengirim (Transmitter)

Gambar 11. merupakan implementasi dari perangkat elektronik bagian pengirim (transmitter) yang terdiri dari remote switch, mikrokontroler Arduino Uno dan modul RF 433 Mhz yang telah dihubungkan dan diintegrasikan antara satu dengan yang lainnya. Untuk implementasi perangkat elektronik bagian penerima (receiver) yaitu rangkaian motor driver, Arduino Mega, dan Modul receiver RF 433 Mhz.

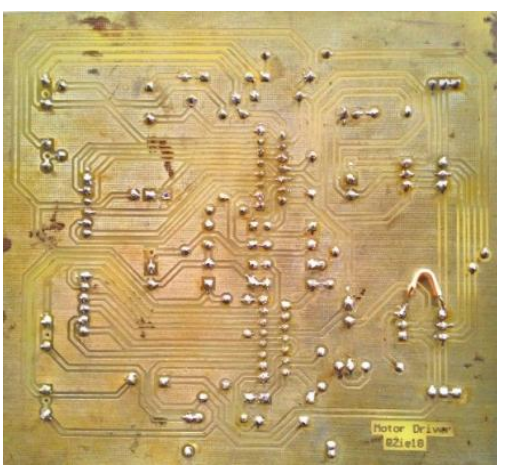

Gambar 12. Implementasi PCB Rangkaian Motor Driver Tampak Bawah

Pada tahap perancangan rangkaian motor driver hanya dibuat dalam bentuk gambar skematik dan layout PCB menggunakan software bernama Altium Designeer. Sedangkan dalam tahapan implementasi gambar layout rangkaian yang telah dibuat di realisasikan dan dicetak pada sebuah papan PCB. Seperti yang terlihat pada gambar 12. Gambar diatas merupakan tampilan tampak bawah dari implementasi rangkaian motor driver yang sudah tercetak pada papan PCB. Setelah semua alat diimplementasikan maka selanjutnya perangkat elektronik bagian penerima (receiver) yang terdiri dari mikrokontroler Arduino Mega 2560, modul receiver RF 433 Mhz, motor driver dan motor DC dihubungkan antara satu dengan yang lainnya sehingga terintegrasi dan dapat digunakan sesuai kebutuhan. Sesuai dengan yang ditunjukan pada gambar 13. dibawah ini.

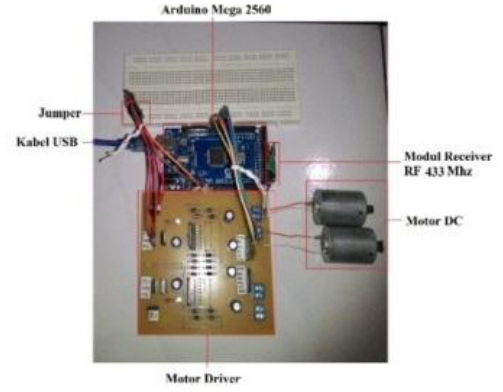

Gambar 13.. Implementasi Bagian Penerima (Receiver) 
Untuk implementasi rangka robot dan tangki ballast yang telah dibuat desainnya pada software AutoCad 2004 dapat dilihat pada gambar 14.

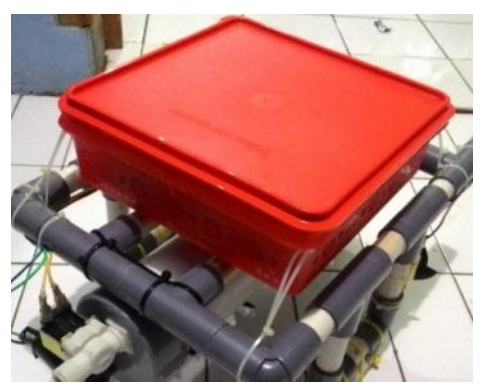

Gambar 14. Implementasi Keseluruhan Rangka dan Tangki Ballast

Tahap terakhir adalah pembuatan program robot yang termasuk kedalam tahapan perancangan perangkat lunak (software). Tahapan ini dilakukan setelah pembuatan rangka dan perangkat keras bagian elektronik. Program robot dibuat pada software Arduino menggunakan bahasa C. Pembuatan program terdiri dari dua bagian yang pertama di bagian pengirim (transmitter) dan kedua di bagian penerima (receiver). Karena penelitian ini menggunakan dua buah mikrokontroler yaitu Arduino Uno di bagian pengirim dan Arduino Mega 2560 di bagian penerima.

Pembuatan program di bagian pengirim (transmitter). diawali dengan inisialisasi atau pengaturan pin pada Arduino Uno. Pada penelitian ini pin yang digunakan adalah pin digital karena input yang dipakai berupa push button switch yang memberikan masukan 1 atau 0. Setiap pin diberi nama sesuai dengan kebutuhan. Untuk pin nomor 5 diberi nama maju, pin nomor 3 diberi nama mundur, pin nomor 4 diberi nama bkan, pin nomor 3 diberi nama bkiri, pin nomor 7 diberi nama naik, pin nomor 6 diberi nama trun. Pin 9, 10 diberi nama pom1 dan pom2. Pin 11,12 diberi nama ran1dan ran2. Gambar 15 di bawah ini merupakan gambar dari flowchart pembuatan program di bagian pengirim (transmitter).

Pembuatan program di penerima sama dengan di pengirim diawali dengan inisialisasi atau pengaturan pin pada Arduino Uno. Pin yang digunakan di bagian penerima adalah pin digital karena pin ini akan di hubungkan ke motor. Pada pin digital terdapat keistimewaan yaitu terdapat PWM (Pulse Width Modulation). Setiap pin diberi nama sesuai dengan kebutuhan. Untuk satu buah motor dibutuhkan 3 buah pin Arduino. Pada penelitian ini motor yang akan digunakan sebanyak 3 buah sehingga akan ada 9 pin yang terpakai untuk motor ditambah lagi dengan katup dan pompa. Sehingga ada sekitar 11 pin yang akan diinisisalisasi untuk output. Satu buah pin akan dihubungkan ke modul RF $433 \mathrm{Mhz}$ untuk penerimaan data. Setelah semua output diinisialisasi maka saat ada data yang diterima dan terbaca oleh mikrokontroler yang memerintahkan output baik motor, katup atau pompa untuk hidup sehingga output akan bergerak. Gambar 15 di bawah ini merupakan gambar dari flowchart pembuatan program di bagian penerima (Receiver). 


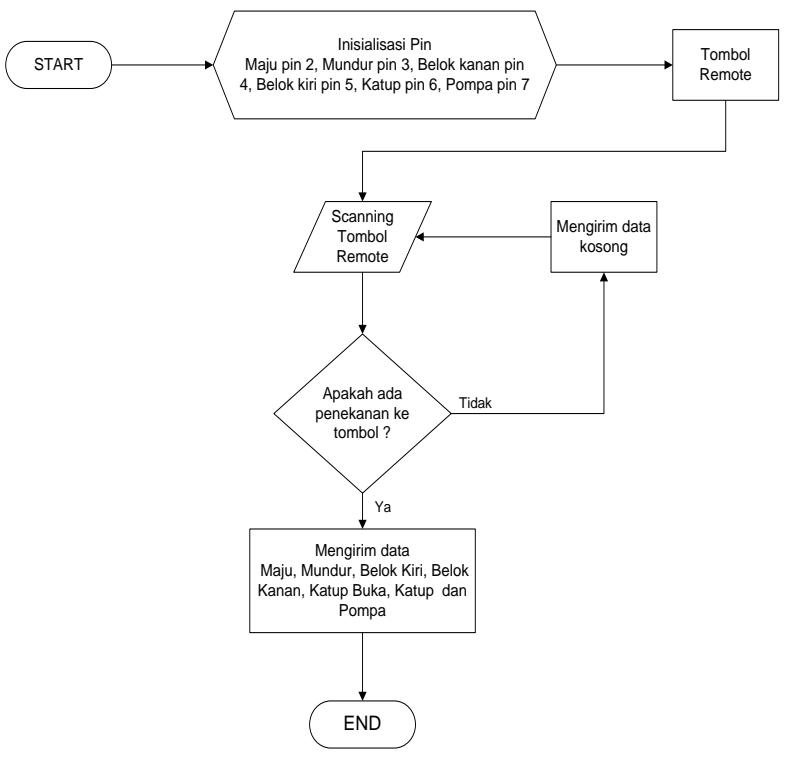

Gambar 15. Flowchart

Pembuatan Program Bagian

Pengirim (Transmitter)

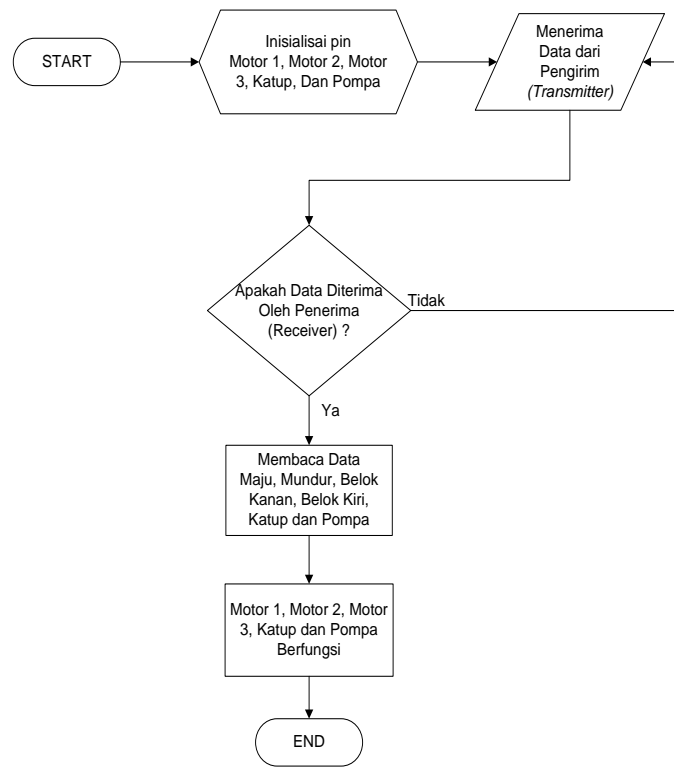

Gambar 16. Flowchart

Pembuatan Program Bagian

Penerima (Receiver)

\section{Pengujian dan Analisis}

Pada bab ini robot akan di uji dan dianalisis. Pengujian dilakukan dengan beberapa tahapan. Pertama pengujian perangkat elektronik. Pengujian ini bertujuan untuk melihat respon robot atau penerima ketika membaca data yang dikirimkan dari remote control. Dalam penelitian ini tombol remote control yang dipakai berjumlah 10 buah. Pengujian tombol remote control dilakukan dengan cara menekan satu persatu tombol yang digunakan.

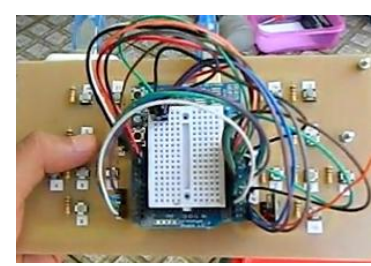

Gambar 17. Pengujian Rangkaian Elektronik Tombol Remote Control

Selanjutnya setelah pengujian perangkat elektronik berhasil dan remote bekerja dengan baik selanjutnya dilakukan pengujian terhadap kerja dari pompa air saat memasukan dan mengeluarkan air kedalam tangki ballast. Parameter yang dilihat yaitu berapa lama waktu yang diperlukan untuk mengisi satu buah tangki ballast yang mempunyai volume $2430,96 \mathrm{~cm}^{3}$. Setelah dilakukan pengujian diperoleh data bahwa waktu yang diperlukan untuk mengisi tabung adalah 60 detik. Seperti yang terlihat pada tabel 1 dan gambar grafik 18 dibawah ini. 


\section{Volume Air Masuk}

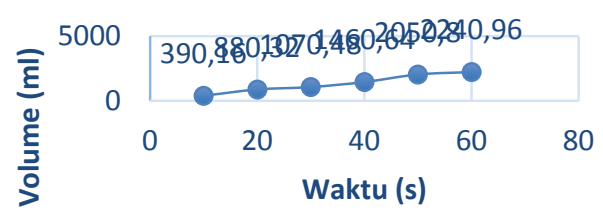

Tabel 1. Pengujian Sistem Ballast Saat Memasukan Air

\begin{tabular}{|c|c|}
\hline Detik (s) & Volume Air \\
\hline 10 & $390,16 \mathrm{ml}$ \\
\hline 20 & $880,32 \mathrm{ml}$ \\
\hline 30 & $1070,48 \mathrm{ml}$ \\
\hline 40 & $1460,64 \mathrm{ml}$ \\
\hline 50 & $2050,8 \mathrm{ml}$ \\
\hline 60 & $2240,96 \mathrm{ml}$ \\
\hline
\end{tabular}

Gambar 18. Grafik Volume Air Masuk

Pada saat mengeluaran air dari dalam tangki waktu yang dibutuhkan sama yaitu 60 detik. Seperti yang terlihat pada tabel 2 .

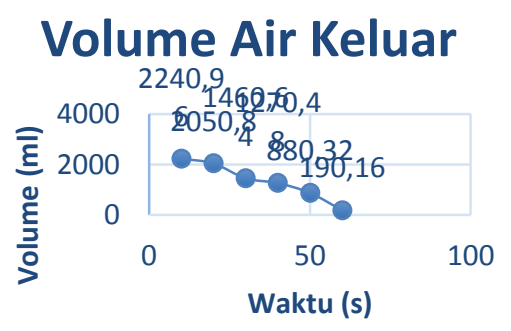

Tabel 2. Pengujian Sistem Ballast Saat Mengeluarkan Air

\begin{tabular}{|c|c|}
\hline Detik (s) & Volume Air \\
\hline 10 & $2240,96 \mathrm{ml}$ \\
\hline 20 & $2050,8 \mathrm{ml}$ \\
\hline 30 & $1460,64 \mathrm{ml}$ \\
\hline 40 & $1270,48 \mathrm{ml}$ \\
\hline 50 & $880,32 \mathrm{ml}$ \\
\hline 60 & $190,16 \mathrm{ml}$ \\
\hline
\end{tabular}

Gambar 19. Grafik Volume Air Keluar

Pengujian selanjutnya yaitu pengujian manuver robot di dalam air. Pengujian ini bertujuan untuk melihat seberapa jauh jarak yang dapat ditempuh oleh robot saat bergerak maju, mundur, belok kiri dan belok kanan. Pengujian ini juga merupakan tahapan terakhir dari semua proses pengujian.Pengujian dilakukan dalam kolam renang dengan kedalman $50 \mathrm{~cm}$ dan keadaan robot di permukaan air,serta robot diuji juga untuk menyelam.

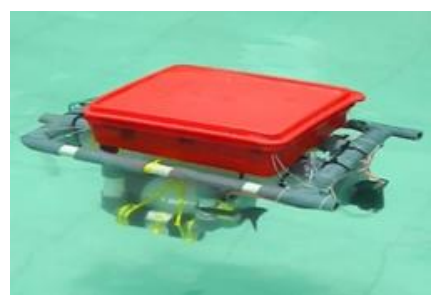

Gambar 20. Pengujian Manuver di Permukaan

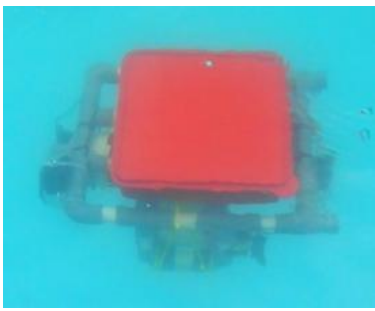

Gambar 21. Pengujian Manuver Saat Tenggelam

Setelah dilakukan pengujian manuver ternyata diperoleh data bahwa jarak yang dapat ditempuh robot yaitu berkisar antara 0 - 10 meter karena dari setiap maneuver yang dilakukan penerimaan ataupun pembacaan data masih baik dengan jarak maksimal 10 meter. Tetapi ketika jarak mulai ditambah sampai jarak 15 meter sinyal yang diterima oleh penerima mulai terputus putus tetapi data masih dapat terkirim. Keadaan ini berlanjut terus sampai jarak tempuh maksimal 18 meter. Lebih dari dari jarak itu sinyal atau data tidak terbaca oleh penerima (receiver).

Sedangkan jarak yang dapat ditempuh untuk penerimaan data di pengirim dan penerima saat robot menyelam yaitu sampai kedalamn maksimal $30 \mathrm{~cm}$ Ditandai dengan motor yang masih dapat bergerak pada kedalaman maksimal. Diatas jarak itu motor dapat bergerak tapi dalam keadaan sinyal terputus - putus. Dari data yang diperoleh ada beberapa penyebab hilangnya sinyal pada saat pengiriman atau penerimaan sinyal. Pertama yaitu terjadinya pelemahan daya pancar sinyal yang disebabkan oleh pergerakan robot yang semakin menjauh dari transmitter sehingga menjadikan daya sinyal tidak tertangkap oleh robot saat jarak lebih dari 15 meter. Selain itu juga tegangan kerja yang dipakai untuk mensuplai modul RF $433 \mathrm{Mhz}$ hanya $5 \mathrm{~V}$ sehingga daya pancarnya kurang maksimal. 
Selain itu juga penyebab robot hanya dapat menyelam dengan kedalaman maksimum $30 \mathrm{~cm}$ yaitu pertama kerapatan molekul antara udara dan air yang berbeda dimana molekul udara yang bergerak bebas bisa lebih mudah ditembus oleh gelombang elektromagnetik sedangkan molekul air yang lebih rapat lebih sulit ditembus oleh gelombang elektromagnetik menjadikan manuver menyelam menjadi kurang maksimal dan sinyal putus - putus.

Selanjutnya dilakukan pengujian untuk melihat kecepatan robot bergerak di dalam air. Pengujian yang pertama robot berada di permukaan air sedangkan pengujian yang kedua robot berada di dalam air. Untuk data pengujian kecepatan yang dilakukan dipermukaan air dengan jarak maksimal 5 meter kecepatan yang didapat berkisar dari $0,0284 \mathrm{~m} / \mathrm{s}-0,0322 \mathrm{~m} / \mathrm{s}$. Untuk grafik dari kecepatan manuver robot dipermukaan terdapat pada gambar 22. Sedangkan untuk kecepatan robot di dalam air ketika menempuh jarak maksimal 5 meter selama 5 kali percobaan relatif berubah tetapi nilainya tidak terpaut jauh. Nilai kecepatan yang diperoleh berkisar dari $0,0290 \mathrm{~m} / \mathrm{s}-0,0297 \mathrm{~m} / \mathrm{s}$. Untuk grafik kecepatan robot di dalam air terdapat pada gambar 23 .

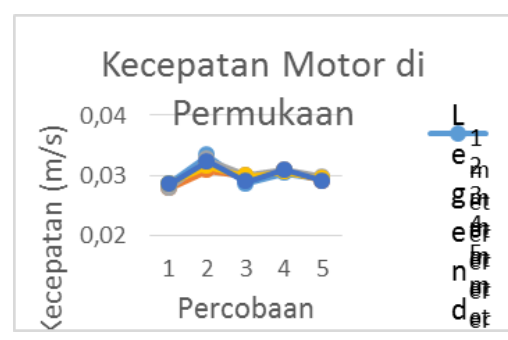

Gambar 22. Grafik Kecepatan Robot di Permukaan Air

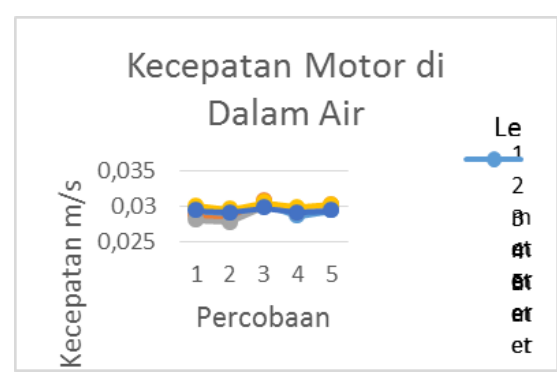

Gambar 23. Grafik Kecepatan Robot di Dalam Air

Setelah dirata - ratakan kecepatan saat melakukan manuver di permukaan waktu tempuhnya menjadi $0,0299 \mathrm{~m} / \mathrm{s}$. Sedangkan data kecepatan manuver robot di dalam air setelah di rata ratakan waktu tempuhnya menjadi $0,0294 \mathrm{~m} / \mathrm{s}$. Dari kedua data tersebut terlihat bahwa kecepatan manuver robot baik dipermukaan atau didalam air tidak jauh berbeda. Hal ini dibuktikan dengan selisih kecepatan setelah di rata - ratakan hanya berjumlah $0,0005 \mathrm{~m} / \mathrm{s}$. Hal ini dikarenakan motor DC yang dipakai robot saat bermanuver dipermukaan atau di dalam air sama. Selain itu juga pada saat bermanuver motor seluruhnya sudah berada di dalam air. Kemudian air yang dipakai untuk melakukan pengujian merupakan air yang sama. Sehingga tidak akan diperoleh data yang jauh berbeda. Adapun selisih kecepatan saat bermanuver di dalam air dan dipermukaan air disebabkan karena adanya hambatan tambahan dari gelombang air yang tidak stabil.

\section{Penutup}

\subsection{Kesimpulan}

Adapun kesimpulan penelitian rangcang bangun robot bawah air menggunakan sistem ballast dengan frekuensi $433 \mathrm{Mhz}$ adalah sebagai berikut :

1. Perangkat elektronik robot bawah air yang terdiri dari bagian pengirim (transmitter) dan bagian penerima (receiver) sudah berhasil dibuat. Dengan Mikrokontroler Arduino Uno dan Arduino Mega 2560 sebagai pusat kendali robot dibagian transmitter dan receiver.

2. Robot dapat bergerak dengan jangkauan maksimal 15 meter dipermukaan dan $30 \mathrm{~cm}$ di dalam air. Dengan kecepatan rata - rata dipermukaan air yaitu $0,0299 \mathrm{~m} / \mathrm{s}$ dan didalam air yaitu $0,0294 \mathrm{~m} / \mathrm{s}$.

3. Sistem ballast dapat berfungsi untuk mengisi dan mengeluarkan air dari dalam tabung. Waktu yang dibutuhkan untuk mengisi tabung dengan volume sebesar $2430,96 \mathrm{~cm}^{3}$ adalah 60 detik sedangkan untuk mengeluarkan air selama 60 detik. Robot dapat melakukan penyelaman dengan kedalaman maksimal $30 \mathrm{~cm}$. 
4. Robot dapat berfungsi dengan baik saat berkomunikasi menggunakan modul RF dengan frekuensi $433 \mathrm{Mhz}$ dibawah 2,4 Ghz.

\subsection{Saran}

Saran untuk penelitian selanjutnya agar teknologi yang telah ada dapat dikembangkan lebih baik lagi adalah sebagai berikut :

1. Penggunaan motor bertorsi besar dan berkecepatan tinggi agar robot bawah air handal dalam melakukan pergerakan di dalam air.

2. Diharapkan sebelum membuat desain rangka maupun tangki ballast dilakukan penghitungan yang tepat agar robot dapat sempurna dalam menyelam, melayang ataupun mengapung di air selain itu juga untuk mempermudah dalam proses memasukan atau mengeluarkan air dari dalam tangki maka sistem ballast harus ditambahkan sebuah tabung yang berisi udara.

\section{Daftar Pustaka}

[1] Ma'mun Ambia, Laode dkk. "Kapal Selam Mini Tanpa Awak Untuk Explorasi Bawah Laut”. Universitas Hasanudin : Makasar.

[2] Santo Gitakarma, Made. 2014. "Alat Bantu Survey Bawah Air Menggunakan AMOBA Robot Berbasis ROV". Unidksha: Singaraja.

[3] Purnomo, Didik Setyo dan Endah Suryawati N. "Rancang Bangun Sistem Ballast Pada ROV (Remotely Underwater Vehicle)". Institut Teknologi Sepuluh Nopember: Surabaya

[4] Bohm, Harry dkk. 2005. "Build Own Your Underwater Robot". Westcoast Word Vancouver: Kanada.

[5] Wardhana, Arif Musa Kusuma. 2009. "Perancangan Sistem Komunikasi Wireless Pada Kapal (MCST-1 Ship AutoPilot) dengan Media Komunikasi RF Untuk mendukung Sistem AutoPilot". Institut Teknologi Sepuluh Nopember: Surabaya 